\title{
FTBMT, a Novel and Selective GPR52 Agonist, Demonstrates Antipsychotic-Like and Procognitive Effects in Rodents, Revealing a Potential Therapeutic Agent for Schizophrenia
}

\author{
Keiji Nishiyama, Hirobumi Suzuki, Toshiya Harasawa, Noriko Suzuki, Emi Kurimoto, \\ Takayuki Kawai, Minoru Maruyama, Hidetoshi Komatsu, Kensuke Sakuma, Yuji Shimizu, \\ and Masato Shimojo
}

CNS Drug Discovery Unit, Research (K.N., H.S., T.H., N.S., E.K., T.K., M.M., H.K., Y.S., M.S.) and Regenerative Medicine Unit (K.S.), Takeda Pharmaceutical Company Limited, Fujisawa, Japan

Received May 17, 2017; accepted August 23, 2017

\begin{abstract}
GPR52 is a Gs-coupled G protein-coupled receptor that is predominantly expressed in the striatum and nucleus accumbens (NAc) and was recently proposed as a potential therapeutic target for schizophrenia. In the current study, we investigated the in vitro and in vivo pharmacologic activities of a novel GPR52 agonist, 4-(3-(3-fluoro-5-(trifluoromethyl)benzyl)-5-methyl-1H-1,2,4-triazol-1-yl)-2-methylbenzamide (FTBMT). FTBMT functioned as a selective GPR52 agonist in vitro and in vivo, as demonstrated by the activation of Camp signaling in striatal neurons. FTBMT inhibited MK-801-induced hyperactivity, an animal model for acute psychosis, without causing catalepsy in mice. The c-fos expression also revealed that FTBMT preferentially induced neuronal activation in the shell of the Nac compared with the striatum, thereby supporting
\end{abstract}

its antipsychotic-like activity with less catalepsy. Furthermore, FTBMT improved recognition memory in a novel objectrecognition test and attenuated MK-801-induced working memory deficits in a radial arm maze test in rats. These recognitive effects were supported by the results of FTBMTinduced $\mathrm{c}$-fos expression in the brain regions related to cognition, including the medial prefrontal cortex, entorhinal cortex, and hippocampus. Taken together, these findings suggest that FTBMT shows antipsychotic and recognitive properties without causing catalepsy in rodents. Given its unique pharmacologic profile, which differs from that of current antipsychotics, FTBMT may provide a new therapeutic option for the treatment of positive and cognitive symptoms of schizophrenia.

\section{Introduction}

Schizophrenia is a severe, chronic, and disabling mental disorder associated with a lifetime risk of approximately $1 \%$ (Saha et al., 2005). The core clinical features of schizophrenia include positive, negative, and cognitive symptoms. Typical antipsychotic agents for the treatment of schizophrenia can reduce the severity of positive symptoms via dopamine $D_{2}$ receptor (D2R) antagonism; however, these treatments induce extrapyramidal symptoms (EPSs). To overcome this side effect, another category of drugs, atypical antipsychotics, has been developed; these agents decrease the incidence of EPS, but concerns with tolerability, in relation to weight gain and endocrinopathies, remain (Krebs et al., 2006). More importantly, these therapeutic agents do not demonstrate satisfactory efficacy for negative and cognitive symptoms, which essentially determine the quality of life and associated costs of care (Miyamoto

This work was supported by Takeda Pharmaceutical Company Limited. https://doi.org/10.1124/jpet.117.242925. et al., 2012). Thus, new classes of drugs for negative and cognitive symptoms have been developed based on several hypotheses; however, no compounds have achieved solid efficacy in those symptoms, although some compounds showed modest activity (Nakazawa et al., 2012; Kingwell, 2014; Li et al., 2015).

GPR52 was first reported as a novel human gene identified by performing homology searches using a basic local alignment search tool with amino acid sequences of known G protein-coupled receptors of publicly available databases such as high-throughput genome or expressed sequence tags databases (Sawzdargo et al., 1999). After its identification from human genomic DNA, the precise distribution of GPR52 mRNA in human tissues was determined (Komatsu et al., 2014). It is predominantly found in the brain, with highest expression levels in the striatum and nucleus accumbens (Nac), which have been implicated in psychosis (Epstein et al., 1999; Sarpal et al., 2015). Interestingly, GPR52 shows near complete colocalization with $\mathrm{D} 2 \mathrm{R}$, but not dopamine $\mathrm{D}_{1}$ receptor (D1R), in these regions (Komatsu et al., 2014). GPR52 is also clearly detected in critical brain regions that are involved in

ABBREVIATIONS: $\mathrm{CHO}$, Chinese hamster ovaty; CREB, cAMP response element binding protein; $\mathrm{D} 2 \mathrm{R}$, dopamine $\mathrm{D}_{2}$ receptor; DLS, dorsolateral striatum; DMS, dorsomedial striatum; ELISA, enzyme-linked immunosorbent assay; EPS, extrapyramidal symptom; FTBMT, 4-(3-(3-fluoro-5(trifluoromethyl)benzyl)-5-methyl-1H-1,2,4-triazol-1-yl)-2-methylbenzamide; GPR, G protein-coupled receptor; ICR, imprinting control region; KO, knockout; MED, minimum effective dose; NAc, nucleus accumbens; NMDA, N-methyl-D-aspartate; NORT, novel object recognition task; qPCR, quantitative polymerase chain reaction; WT, wild-type. 
cognitive functions, including the prefrontal cortex, entorhinal cortex, cingulate cortex, and mammillary nucleus (Komatsu et al., 2014). In contrast to the striatum, GPR52 is partially colocalized with D1R, but not D2R, in the prefrontal cortex (Komatsu et al., 2014).

The facts that intrinsic ligands for GPR52 are not identified and that GPR52 shares limited homology with other G protein-coupled receptors, such as GPR21 (71\%), histamine H2 $(27 \%)$, and 5-HT4 (26\%) human receptors (Sawzdargo et al., 1999), make it difficult to analogize its function, and its function has not been elucidated to date. In such a situation, we have been trying to reveal its biologic function. Reserpine, an antihypertensive agent (Fraser, 1996), and a series of small compounds raise intracellular cAMP levels in recombinant cells expressing GPR52, which indicated that GPR52 is coupled to a Gs protein (Komatsu et al., 2014; Setoh et al., 2014). Given that D2R is a Gi-coupled receptor, which decreases intracellular cAMP levels when activated, the stimulation of GPR52 may counteract D2R signaling of the medium spiny neurons in the striatum and Nac. Indeed, the systemic administration of a GPR52 agonist, 3-(2-(3-chloro-5-fluorobenzyl)-1-benzothiophen-7-yl)- $N$-(2-methoxyethyl)benzamide (compound $7 \mathrm{~m}$ ), and overexpression of GPR52 attenuate methamphetamineinduced hyperactivity in mice (Komatsu et al., 2014; Setoh et al., 2014). Moreover, compound $7 \mathrm{~m}$ did not produce a cataleptic response; however, the underlying mechanism of action for the antipsychotic-like activity of GPR52 agonists, which do not induce catalepsy, and their effects on cognitive function remain unknown.

We recently developed a novel GPR52 agonist, 4-(3-(3fluoro-5-(trifluoromethyl)benzyl)-5-methyl-1 $H$-1,2,4-triazol-1yl)-2-methylbenzamide (FTBMT), which has shown favorable physicochemical and pharmacokinetic properties (Tokumaru et al., 2017). The aim of the current study was to elucidate in vitro and in vivo pharmacologic activities of FTBMT as a potential therapeutic agent in schizophrenia. To determine whether FTBMT functioned as a selective GPR52 agonist in vitro and in vivo, we first investigated the effect of FTBMT on cAMP signaling in Chinese hamster ovary (CHO) cells expressing GPR52, primary cultured striatal neurons, and striatal tissues. We next evaluated the antipsychotic-like effect of FTBMT on MK-801-induced hyperactivity and its cataleptogenic activity in mice, and then we assessed FTBMTinduced neural activation in the striatum and Nac using c-fos immunohistochemistry (Pinna et al., 1997; Satow et al., 2009). Furthermore, we tested whether FTBMT improved cognitive functions in a novel object recognition task (NORT) and a radial arm maze task in rats (Young et al., 2009) and, finally, investigated neural activation in brain regions involved in cognitive functions (Preston and Eichenbaum, 2013).

\section{Materials and Methods}

Animals. Male C57BL/6J, C57BL/6N, imprinting control region (ICR) mice, and Wistar rats were obtained from CLEA Japan, Inc. (Tokyo, Japan). Male Long-Evans rats were obtained from Japan SLC Inc. (Hamamatsu, Japan). Pregnant Sprague-Dawley rats were supplied by Charles River Laboratories Japan, Inc. (Yokohama, Japan). Homozygous GPR52 knockout (KO) mice were generated on an $129 \mathrm{SvEv}$ background (Original 129SvEv mice were derived from the University of Cambridge, Cambridge, UK) and bred at the research animal facilities at Takeda); these GPR52 KO mice were also backcrossed once or three times with $\mathrm{C} 57 \mathrm{BL} / 6 \mathrm{~J}$ strains as previously described (Komatsu et al., 2014). Their correspondent wild-type (WT) littermate mice on each background were generated and used as control animals. The animals were maintained in a light-controlled room on a 12-hour light/dark cycle (lights on at 0700 hours) and were acclimated for approximately 1 week before the experiment. The care and use of the animals and the experimental protocols were approved by the Experimental Animal Care and Use Committee of Takeda Pharmaceutical Company Ltd, which adhered to the Act on Welfare and Management of Animals, a Japanese law (Amendment Act no. 46 of 2014).

Drugs. FTBMT (Tokumaru et al., 2017) (Fig. 1A) was synthesized at Takeda Pharmaceutical Company Ltd (Osaka, Japan). Olanzapine was extracted from Zyprexa (Eli Lilly and Co., Indianapolis, IN) at KNC Laboratories Co. Ltd. (Kobe, Japan). FTBMT and olanzapine were suspended in $0.5 \%(\mathrm{w} / \mathrm{v})$ methylcellulose in distilled water. Aripiprazole was obtained from AK Scientific Inc. (Union City, CA) and suspended in a $1 \%(\mathrm{v} / \mathrm{v})$ solution of Tween 80 in distilled water. Methamphetamine hydrochloride (Dainippon Sumitomo Pharma, Osaka, Japan) and (+)-MK-801 hydrogen maleate (MK-801; Wako, Osaka, Japan, and Sigma-Aldrich, St. Louis, MO) were dissolved in saline. All compounds were administered at a dose of 10 or $20 \mathrm{ml} / \mathrm{kg}$ of body weight in mice and $2 \mathrm{ml} / \mathrm{kg}$ of body weight in rats.

Tissue Sampling. For quantitative polymerase chain reaction (qPCR) analyses, male ICR mice (8-10 weeks old), GPR52 KO mice, and their WT littermates (2-10 months old) on C57BL/6J background were sacrificed 1 or 2 hours after oral administration of FTBMT at a dose of 3-100 mg/kg. After whole brains were collected, the entire striatum and hippocampus were immediately isolated with fine forceps on ice; however, in the comparison study between the striatum and NAc, each tissue was separated from coronal slices $(1 \mathrm{~mm})$ and prepared using a Precision Brain Slicer (Braintree Scientific, Braintree, MA) as previously described (Sakuma et al., 2015). All tissues were frozen on dry ice and stored at $-80^{\circ} \mathrm{C}$ until analysis. For the phospho-cAMP response element binding protein (CREB) analyses, the mice were sacrificed 1 hour after oral administration of FTBMT (3-30 mg/kg) using a focused microwave irradiation system (MMW-05; Muromachi Kikai, Tokyo, Japan). Striatum and hippocampal tissues were then isolated using fine forceps on ice and lysed with denaturing cell-extraction buffer (no. FNN0011; Thermo Fisher Scientific, Waltham, MA) containing a protease inhibitor cocktail and p-APMSF (Sigma-Aldrich). The lysates were stored at $-80^{\circ} \mathrm{C}$ until analysis.

Cell Culture. CHO cells (no. CRL-9096; American Type Culture Collection, Manassas, VA) stably expressing GPR52 receptors (human, mouse, and rat genes) and naïve CHO cells were cultured in Ham's F-12 (Thermo Fisher Scientific) supplemented with $10 \%$ fetal bovine serum (Moregate Biotech, Brisbane, Australia) and $100 \mathrm{U} / \mathrm{ml}$ of penicillin-streptomycin (Thermo Fisher Scientific). For the preparation of rat primary striatal neurons, striatal tissue, which was dissected from rat embryos on embryonic day 18 or 19, was dissociated using nerve-cells dispersion solutions (Sumitomo Bakelite, Tokyo, Japan). Cells were plated on a 96 -well poly-D-lysine-coated plates (BD Biosciences, San Jose, CA) at a density of $3 \times 10^{4}$ cells/well, for the GABA release assay, or a 24-well poly-D-lysine-coated plates (BD Biosciences) at a density of $1.86 \times 10^{5}$ for other assays. Cells were then cultured with neurobasal medium (Thermo Fisher Scientific) containing B27 supplement (Thermo Fisher Scientific), $2 \mathrm{mM}$ L-glutamine (Lonza, Basel, Switzerland), $20 \mu \mathrm{g} / \mathrm{ml}$ gentamicin (Lonza), $100 \mathrm{U} / \mathrm{ml}$ penicillin (Lonza), and $100 \mu \mathrm{g} / \mathrm{ml}$ streptomycin (Lonza) at $37^{\circ} \mathrm{C}$ in a humidified atmosphere of $95 \%$ air and $5 \% \mathrm{CO}_{2}$. On day 13-16 in vitro, cells were treated with FTBMT in Hanks' balanced salt solution (Thermo Fisher Scientific Inc.) containing 5 mM HEPES (DOJINDO Laboratories, Kumamoto, Japan), $\mathrm{pH} 7.5$, and $0.5 \%$ fatty acid free bovine serum albumin (Wako, Osaka, Japan) for 15 or 60 minutes at $37^{\circ} \mathrm{C}$ and then homogenized in RLT buffer (Qiagen, Germantown, MD) or lysed with denaturing cell extraction buffer (Thermo Fisher Scientific) containing a protease inhibitor cocktail and p-APMSF (Sigma-Aldrich). Lysates were stored at $-80^{\circ} \mathrm{C}$ until analysis. 
A<smiles>Cc1cc(-n2nc(Cc3cc(F)cc(C(F)(F)F)c3)nc2C)ccc1C(N)=O</smiles>

D

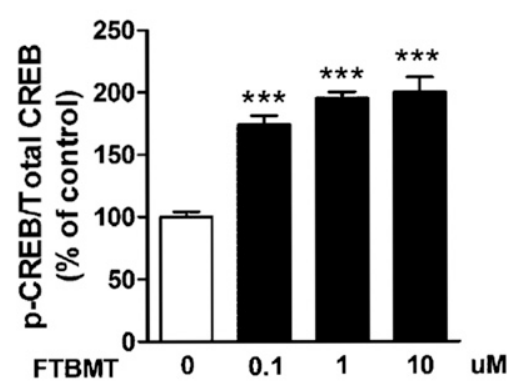

B

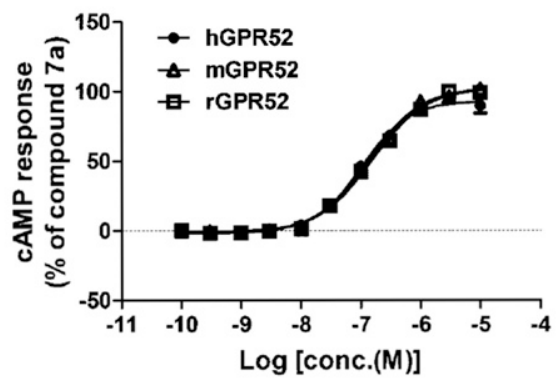

$\mathbf{E}$

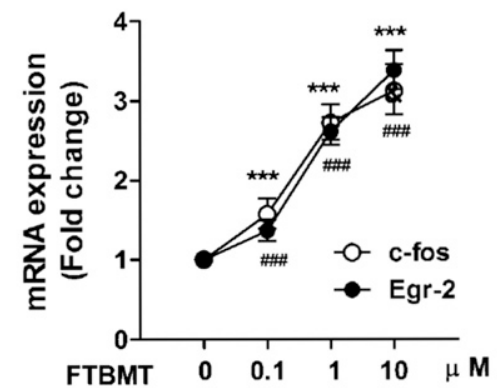

C

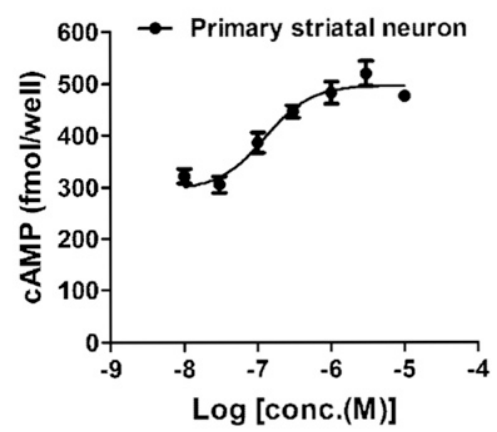

$\mathbf{F}$

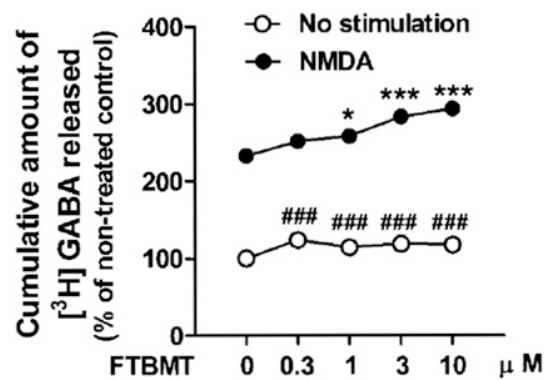

Fig. 1. FTBMT-induced activation of cAMP signaling in vitro. (A) Chemical structure of FTBMT. (B) FTBMT-stimulated cAMP response in CHO cells expressing human, mouse, or rat GPR52 $(n=4)$. Dose-dependent effects of FTBMT on (C) cAMP production $(n=3)$, (D) phosphorylated CREB $(n=3)$, (E) IEG (c-fos and Egr-2) expression $(n=3)$, and (F) basal and $20 \mu \mathrm{M}$ NMDA-stimulated release of $\left[{ }^{3} \mathrm{H}\right]$-GABA $(n=4-8)$ in primary striatal neurons. The cultured neurons (13-16 days in vitro) were stimulated with FTBMT for 15 (C, D, and E), $30(\mathrm{G})$, or 60 (F) minutes. All data are presented as means \pm

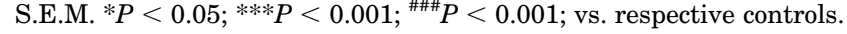

cAMP Assay. CHO cells stably expressing GPR52 receptors and naïve CHO cells $(10,000$ cells/well) were stimulated with FTBMT in cAMP assay buffer for 30 minutes at $37^{\circ} \mathrm{C}$. Intracellular cAMP levels were determined using an Alphascreen cAMP detection kit (PerkinElmer, Waltham, MA), according to the manufacturer's instructions. $\mathrm{EC}_{50}$ values were analyzed using nonlinear regression analyses with GraphPad PRISM software (GraphPad Software Inc., San Diego, CA). In the cAMP assay using recombinant CHO cells, the response at $1 \mu \mathrm{M}$ of $N$-(2-hydroxyethyl)-3-(2-(3-(trifluoromethyl)benzyl)-1-benzofuran-4-yl)benzamide (compound 7a) was used as the $100 \%$ control as described previously (Setoh et al., 2014).

Off-Target Profiling. Selectivity against other receptors, ion channels, and enzymes was determined in Ricerca Biosciences, which is now Eurofins (Luxembourg), according to the experimental conditions specified at company website (http://www.eurofins.com/biopharmaservices/discovery/services/in-vitro-pharmacology/).

Preparation and Processing of Acute NAc Slices. NAc slices were prepared as described in a previous article but with minor modifications (Nishi et al., 2008). NAc slices were prepared from male ICR mice (8-10 weeks old). Coronal slices $(500 \mu \mathrm{m})$ were prepared using a vibrating blade microtome DTK-1000 (D.S.K., Kyoto, Japan). Each NAc slice was placed in a polypropylene incubation tube (SARSTEDT, North Rhine-Westphalia, Nümbrecht, Germany) with $2 \mathrm{ml}$ of fresh Krebs- $\mathrm{HCO}_{3}$-buffer containing $124 \mathrm{mM} \mathrm{NaCl}, 4 \mathrm{mM} \mathrm{KCl}$, $26 \mathrm{mM} \mathrm{NaHCO}_{3}, 1.5 \mathrm{mM} \mathrm{CaCl}_{2}, 1.25 \mathrm{mM} \mathrm{KH}_{2} \mathrm{PO}_{4}, 1.5 \mathrm{mM} \mathrm{MgSO}_{4}$, and $10 \mathrm{mM}$ D-glucose (all reagents were supplied by Wako), $\mathrm{pH} 7.4$, with $10 \mu \mathrm{g} / \mathrm{ml}$ of adenosine deaminase (Roche Life Science, Indianapolis, IN). The slices recovered at $30^{\circ} \mathrm{C}$ under constant oxygenation with $95 \% \mathrm{O}_{2} / 5 \% \mathrm{CO}_{2}$ for 60 minutes. After the first 30 minutes of incubation, the buffer was replaced with fresh $\mathrm{Krebs}-\mathrm{HCO}_{3}$ buffer without adenosine deaminase, followed by an additional 30 minutes of incubation. Subsequently, slices were treated with FTBMT for 5 minutes, transferred to tubes, and frozen on dry ice. Frozen tissue samples were denatured using sonication and boiling in $1 \%(\mathrm{w} / \mathrm{v})$ SDS
(Wako) containing $50 \mathrm{mM}$ sodium fluoride (Wako), and protease inhibitor cocktail (Sigma-Aldrich).

$\left[{ }^{3}\right.$ H]-GABA Release Assay. The culture medium for primary striatal neurons (96-well plate) was replaced with assay buffer, which had the following composition: $10 \mathrm{mM}$ HEPES, $135 \mathrm{mM} \mathrm{NaCl}, 5 \mathrm{mM}$ $\mathrm{KCl}, 0.6 \mathrm{mM} \mathrm{MgSO}_{4}, 1 \mathrm{mM} \mathrm{CaCl}, 6 \mathrm{mM}$ D-glucose, and $100 \mu \mathrm{M}$ aminooxyacetic acid (all reagents were supplied by Wako), $\mathrm{pH}$ 7.4. Cells were incubated with $0.3 \mu \mathrm{M}\left[{ }^{3} \mathrm{H}\right]$-GABA (NET191X; PerkinElmer) in assay buffer for 60 minutes at $37^{\circ} \mathrm{C}$ and then washed three times with assay buffer. To measure the basal release of $\left[{ }^{3} \mathrm{H}\right]$-GABA, cells were incubated with FTBMT in assay buffer for 30 minutes at $37^{\circ} \mathrm{C}$, after which the assay buffer was collected. To measure the $N$-methyl-D-aspartate (NMDA; Wako)-evoked release of $\left[{ }^{3} \mathrm{H}\right]$-GABA, cells were preincubated with FTBMT in assay buffer for 10 minutes at $37^{\circ} \mathrm{C}$, after which the cells were stimulated with $20 \mu \mathrm{M}$ NMDA for 20 minutes at $37^{\circ} \mathrm{C}$. Thereafter, the assay buffer was collected, and radioactivity was measured using a microplate scintillation counter (TopCount NXT, PerkinElmer).

Western Blotting and ELISA. The protein concentrations of lysates from striatal neurons, NAc slices, and microwaved brain tissues were determined using a bicinchoninic acid assay kit (Thermo Fisher Scientific). For Western blotting, the lysates (10 $\mu \mathrm{g}$ of protein/lane) were subjected to SDS-PAGE using 4\%-12\% NuPAGE Bis-Tris gel (Thermo Fisher Scientific) and then transferred to a nitrocellulose membrane (Thermo Fisher Scientific). The membranes were incubated in blocking buffer [phosphate-buffered saline (Thermo Fisher Scientific) containing $5 \%(\mathrm{w} / \mathrm{v})$ nonfat dry milk (Wako) and $0.1 \%(\mathrm{w} / \mathrm{v})$ Tween 20 (SigmaAldrich)] for 60 minutes at room temperature. The membranes were probed with antibodies to dopamine and cAMP-related phosphoprotein, 32 kDa (DARPP32; no. 2302, 1:500; Cell Signaling Technology, Danvers, MA) and phospho-DARPP32 (Thr34, no. P1025-34, 1:300; Phosphosolutions, Aurora, CO). Immunoreactive bands were visualized using horseradish peroxidase-linked anti-rabbit IgG antibodies (no. 7074, 1:5000; GE Healthcare, Buckinghamshire, UK) and an ECL plus system 
(GE Healthcare). Protein levels were quantified by densitometry using Quantity One (Bio-Rad, Hercules, CA). Amounts of phosphoCREB and total CREB in striatal neurons and microwaved tissues were determined using the CREB [pS133] phospho-enzyme-linked immunosorbent assay (ELISA) and CREB (total) ELISA Kits (Thermo Fisher Scientific) according to the manufacturer's instructions.

Quantitative Gene-Expression Analysis. Total RNA purification and $\mathrm{PPCR}$, which have been previously outlined in detail (Sakuma et al., 2015), were applied to the striatum, and NAc samples were isolated from coronal slices. Other samples were processed and analyzed using the previously cited method, with modifications. Briefly, total RNA was purified using QIAzol lysis reagent (Qiagen, Hilden, Germany), followed by use of the RNeasy kit (Qiagen) and DNase I (Qiagen). The RNA was reverse-transcribed to cDNA using high-capacity cDNA reverse transcription kits (Thermo Fisher Scientific). Real-time qPCR was performed using a 7900HT sequence detection system (Thermo Fisher Scientific), with TaqMan Universal PCR Master Mix and Gene Expression Assay primer and probe sets (assay ID for c-fos, Mm00487425_m1 and Rn02396759_m1; Egr-2, Mm00456650_m1 and Rn00586224_m1; Arc, Mm00479619_g1; GAPDH, 4352338E and 4352339E; Thermo Fisher Scientific). The quantities of target genes were determined using absolute quantification or relative quantification according to the $\Delta \Delta \mathrm{Ct}$ method.

Immunohistochemical Staining. Vehicle or FTBMT (30 mg/kg) were i.p. administered to male $\mathrm{C} 57 \mathrm{BL} / 6 \mathrm{~N}$ mice (9 weeks old). After 2 hours, the animals were anesthetized and perfused with saline (Otsuka, Tokushima, Japan), followed by saline with $4 \%$ paraformaldehyde (Wako), via the left cardiac ventricle before brain sampling. The sampled brains were cryoprotected with $30 \%$ sucrose (Wako), and frozen coronal sections $(40 \mu \mathrm{m})$ were prepared using a freezing cryostat CM1850 (Leica, Nussloch, Germany) and used for staining. The sections were incubated with anti-c-Fos antibody (sc-52, 1:4000; Santa Cruz Biotechnology, Santa Cruz, CA) and visualized using a VECTASTAIN Elite ABC kit (PK-6101; Vector Laboratories, Burlingame, CA) and diaminobenzidine (DOJINDO Laboratories). All the procedures were performed using the free-floating method. After processing, the sections were mounted, and images, including the unilateral nucleus, were acquired using light microscopy ECLIPSE E800 (Nikon, Tokyo, Japan). The number of c-Fos-positive cells was automatically measured from the obtained images using Image-Pro Plus (MediaCybernetics, Rockville, MD). The counts from two to four sections from each animal were averaged; the mean value was used for subsequent statistical analyses.

Locomotor Activity. The locomotor activity in male ICR mice (7 to 8 weeks old) homozygous GPR52-KO mice and their WT littermates (2-10 months old) on a $129 \mathrm{SvEv}$ background was measured using locomotor activity monitors (MDC-LT; Brain Science Idea Co., Ltd, Osaka, Japan). Mice were individually placed in transparent polycarbonate cages $(30 \times 40 \times 20 \mathrm{~cm})$ and acclimated for more than 60 minutes. FTBMT (3-30 mg/kg) or vehicle was orally administered 60 minutes before s.c. administration of MK- $801(0.2 \mathrm{mg} / \mathrm{kg})$ or vehicle. Activity counts were measured for 60 minutes after administration of FTBMT or vehicle until administration of MK-801 and 90 minutes after administration of MK-801 or vehicle.

Bar Test. Male ICR mice ( 6 to 7 weeks old) were treated orally with vehicle, FTBMT, olanzapine, or aripiprazole 60 minutes before the bar test. The mice were lifted by the tail and placed with their front paws on a steel bar (diameter, $2 \mathrm{~mm}$ ), which was elevated $6.5 \mathrm{~cm}$ above the table. Their hind legs were on the plane surface. The time during which both forelimbs remained on the bar (cataleptic response) was measured, with a maximum time limit of 30 seconds. The procedure was repeated three times, and the cataleptic response time was averaged for each mouse.

Plasma Prolactin Concentrations. Male Wistar rats (7 weeks old) received an oral dose of FTBMT (1-100 mg/kg), haloperidol $(1 \mathrm{mg} / \mathrm{kg})$, or vehicle. Trunk blood was collected in EDTA-coated tubes 1 hour later and centrifuged at $1600 \mathrm{~g}$ for 20 minutes at $4^{\circ} \mathrm{C}$. Plasma was stored at $-20^{\circ} \mathrm{C}$ until analysis. Plasma prolactin concentrations were measured using a Rat Prolactin Enzyme Immunoassay Kit (SPI-bio, Montigny-le-Bretonneux, France).

NORT. The NORT was slightly modified from the previously described method (Bevins and Besheer, 2006; Shiraishi et al., 2016). On the first day, male Long-Evans rats ( 7 weeks old) were acclimated to the behavioral test room for a minimum of 1 hour and then individually familiarized with the empty test box (a gray polyvinyl chloride box measuring $40 \times 40 \times 50 \mathrm{~cm}$ ) for 10 minutes. Testing comprised two 3-minute trials, which were called the acquisition and retention trials. These trials were separated by a 48-hour intertrial interval. On day 2 , in the acquisition trial, rats were allowed to explore two identical objects (A1 and A2) for 3 minutes. On day 4, in the retention trial, rats were again allowed to explore a familiar object (A3) and a novel object (B) for 3 minutes. Object exploration was defined as licking, sniffing, or touching the object with their forelimbs while sniffing. Leaning against the object to look upward, standing, or sitting on the object was excluded. The exploration time for each object (A1, A2, A3, and B) in each trial was scored manually. FTBMT, at a dose of 3 or $10 \mathrm{mg} / \mathrm{kg}$, or vehicle was orally administered immediately after the acquisition trial. The novelty discrimination index (NDI) was calculated using the following equation: novel object interaction/total interaction $\times 100(\%)$. The person who performed the measurement was blinded to whether FTBMT or vehicle had been administered to each rat.

Radial Arm Maze Test. The experiment was performed using male Long-Evans rats (9 weeks old), as previously described (Zou et al., 1998; Shiraishi et al., 2016), with modifications. An eight-arm radial maze (each arm was $50 \mathrm{~cm}$ long, $10 \mathrm{~cm}$ wide, and $40 \mathrm{~cm}$ high; the maze was elevated $50 \mathrm{~cm}$ above the floor) was used to evaluate the working memory of Long-Evans rats (9 weeks old). After fasting for 24 hours, all rats were food-restricted to $85 \%$ of free-feeding body weight on the first day of exposure to the maze. Reinforcement consisted of three food pellets (45-mg dustless precision pellets; Bio-Serv Inc., Frenchtown, NJ), which were placed in the food cup at the end of each arm. On the first day of habituation to the maze, reinforcement pellets were placed near the entrance and at the midpoints of each arm. Three rats were placed on the maze and allowed to explore and consume the pellets for 8 minutes. On day 2 of habituation, the rats were allowed to explore independently and consume the pellets placed at the midpoints and in the food cups at the end of each arm for 5 minutes. Training sessions started on day 3 , and pellets were placed in the food cups at the end of each arm. The rats were placed on the maze facing away from the person performing the experiment and facing the same arm at the start of each trial. The entry of rats into each arm was recorded in sequence. Rats were allowed to explore until they completed one entry into each arm or 5 minutes had elapsed. Entries into previously chosen arms and failure to consume the pellets were counted as an error. The learning criterion was defined as fewer than two errors in 2 consecutive days. FTBMT, at $10 \mathrm{mg} / \mathrm{kg}$, or vehicle was orally administered 1 hour before the test. MK-801 $(0.08 \mathrm{mg} / \mathrm{kg}$, s.c., as a salt), or saline was administered 30 minutes before the test. The person who performed the measurement was blinded to whether the rat had been administered FTBMT or vehicle.

Statistical Analysis. All statistical analyses were performed using the EXSUS statistical software package (CAC Croit Corporation, Tokyo, Japan). The Aspin-Welch test (Algina, 2005) was used to evaluate significant differences between the two groups. In doseresponse experiments, the homogeneity of variances was assessed using a Bartlett's test (Snedecor and Cochran, 1989), after which a two-tailed Williams test (Williams, 1971) or two-tailed ShirleyWilliams test (Shirley, 1977) was performed for parametric and nonparametric data, respectively. A two-way analysis of variance (ANOVA), followed by an Aspin-Welch test or two-tailed Williams' tests as a post-hoc test, was used for the experiments evaluating the GPR52-mediated effects of FTBMT in GPR52 KO mice. In the NORT experiments, the differences between exploration times spent with familiar and novel objects for each group were analyzed using paired $t$ tests. Statistical significance was set at $P<0.05$. 


\section{Results}

FTBMT-Activated cAMP Signaling In Vitro. FTBMT increased intracellular cAMP levels in CHO cells expressing human, mouse, or rat GPR52, with $\mathrm{pEC}_{50}$ values of $7.03 \pm$ $0.04,6.85 \pm 0.02$, and $6.87 \pm 0.02$, respectively (Fig. 1B); however, FTBMT, at doses up to $10 \mu \mathrm{M}$, did not demonstrate an effect on naïve CHO cells (data not shown). The selectivity of FTBMT was further tested against 98 other targets, including receptors, ion channels, and enzymes (Ricerca Biosciences, Concord, OH). FTBMT $(10 \mu \mathrm{M})$ did not show significant inhibition or stimulation $(50 \%)$ in these biochemical assays (Tables 1, 2, 3, and 4). In rat primary striatal neurons that highly express endogenous GPR52, FTBMT elevated the levels of cAMP (Fig. $1 \mathrm{C} ; \mathrm{pEC}_{50}=6.82$ \pm 0.05 ) and phosho-CREB (Fig. 1D), which increased the expression of downstream CREB target genes, c-fos, and Egr-2 (Fig. 1E). The stimulation of Gs-coupled adenosine $\mathrm{A}_{2 \mathrm{~A}}$ receptor (A2A-R) expressed on GABAergic neurons in the striatum increased GABA release via the cAMP signaling pathway (Shindou et al., 2002; Ferre et al., 2008). Similarly, FTBMT increased the basal and NMDAstimulated release of $\left[{ }^{3} \mathrm{H}\right]-\mathrm{GABA}$ in primary striatal neurons (Fig. 1F). In NAc slices highly expressing GPR52, as well as in the striatum, FTBMT also activated cAMP signaling, which was demonstrated by the increased levels of phospho-DARPP-32 at Thr34 catalyzed by protein kinase A (Fig. 2).

FTBMT Exhibited Antipsychotic-Like Activity without Causing Catalepsy in Mice. Consistent with the in vitro results, oral administration of FTBMT $(30 \mathrm{mg} / \mathrm{kg})$ to

\section{TABLE 1}

Effects of FTBMT on various enzyme activities

FTBMT was tested at $10 \mu \mathrm{M}$ in the all assays. Negative value of percent inhibition indicate activation of enzyme activity.

\begin{tabular}{lc}
\hline \multicolumn{1}{c}{ Enzyme } & \% Inhibition \\
\hline ATPase, $\mathrm{Ca}^{2+}$, skeletal muscle & -1 \\
ATPase, $\mathrm{Na}^{+} / \mathrm{K}^{+}$, heart & -2 \\
Carbonic anhydrase II & 4 \\
Choline esterase, acetyl, ACES & 18 \\
COX-1 & -1 \\
COX-2 & -20 \\
HMG-CoA reductase & -13 \\
Lipoxygenase (5-LO) & -5 \\
MAO-A & 6 \\
MAO-B & 26 \\
NOS, inducible (iNOS) & 7 \\
NOS, neuronal (nNOS) & 11 \\
Peptidase, factor Xa & -4 \\
MMP-1 & -3 \\
MMP-7 & 0 \\
MMP-13 & 1 \\
PDE3 & 28 \\
PDE4 & 6 \\
PDE5 & 24 \\
PDE6 & 17 \\
PDE10A1 & 0 \\
Protein kinase A (PKA), nonselective & 17 \\
Protein kinase C (PKC), nonselective & -5 \\
ROCK1 & 9 \\
Protein tyrosine kinase, EGF receptor & -1 \\
Steroid 5 $\alpha$-reductase & 0 \\
Xanthine oxidase & 10 \\
\hline
\end{tabular}

COX, cyclooxygenase; EGF, epidermal growth factor; HMG CoA, 3-hydroxy-3methyl-glutaryl coenzyme A; MAO, monoamine oxidase; MMP, matrix metalloproteinase; NOS, nitric oxide synthase; PDE, phosphodiesterase; ROCK1, Rho associated coiled-coil containing protein kinase 1 .
WT mice increased phospho-CREB levels in the striatum. The effect was diminished in GPR52 KO mice (Fig. 3A; $P<0.001$; significant main effect of the strain: $F_{1,29}=15.95, P<0.05$; significant strain $\times$ dose interaction: $F_{2,29}=3.38, P<0.05$; post-hoc two-tailed Williams' test).

GPR52 agonists, including FTBMT, have previously been shown to decrease methamphetamine-induced hyperactivity (Tokumaru et al., 2017), a model that is widely used to assess antipsychotic-like effects based on the dopamine hyperfunction hypothesis of schizophrenia (Jones et al., 2011). The antipsychotic-like activity of FTBMT was further evaluated in a MK-801-induced hyperactivity model, which is based on the glutamate hypofunction hypothesis of schizophrenia (O'Neill and Shaw, 1999; Goff and Coyle, 2001). In mice, FTBMT demonstrated a dose-dependent inhibition of MK-801-induced hyperactivity at doses from 3 to $30 \mathrm{mg} / \mathrm{kg}$ (Fig. 3B). This effect was absent in GPR52 KO mice, even at the highest dose of $30 \mathrm{mg} /$ $\mathrm{kg}$ of FTBMT (Fig. 3D; $P<0.01$; significant main effect of the strain: $F_{1,68}=9.13, P<0.01$; significant main effect of the drug: $F_{1,68}=27.43, P<0.001$; significant strain $\times$ drug interaction: $F_{1,68}=12.62, P<0.001$; post-hoc Aspin-Welch test). On the other hand, FTBMT also decreased basal locomotor activity (Fig. 3C).

A potential side effect of FTBMT on motor function was evaluated using bar tests in mice. Oral administration of FTBMT at doses up to $100 \mathrm{mg} / \mathrm{kg}$ did not cause any cataleptic responses in the bar test (Fig. 3E), whereas olanzapine- and aripiprazole-induced catalepsy at their respective minimum effective dose (MED) for methamphetamine-induced hyperactivity

TABLE 2

Effects of FTBMT in various receptor binding assays (1)

FTBMT was tested at $10 \mu \mathrm{M}$ in the all assays. Negative value of percent inhibition indicates stimulation of receptor activity.

\begin{tabular}{lr}
\hline \multicolumn{1}{c}{ Receptor } & \% \\
\hline Adenhibition \\
\hline Adenosine A1 & 33 \\
Adenosine A2B & 0 \\
Adrenergic $\alpha$ 1, nonselective & 12 \\
Adrenergic $\alpha 2$, nonselective & 3 \\
Adrenergic $\beta 1$ & 5 \\
Adrenergic $\beta 2$ & -1 \\
Adrenergic $\beta 3$ & -5 \\
Androgen (testosterone) & 0 \\
Angiotensin AT1 & 5 \\
Angiotensin AT2 & 9 \\
Bradykinin B1 & 1 \\
Bradykinin B2 & -5 \\
Calcium channel L-type, benzothiazepine & 16 \\
Calcium channel L-type, dihydropyridine & 19 \\
Calcium channel L-type, phenylalkylamine & -2 \\
Calcium channel N-type & -6 \\
Cannabinoid CB1 & -9 \\
Cholecystokinin CCK1 (CCKA) & -4 \\
Cholecystokinin CCK2 (CCK B $)$ & 6 \\
Dopamine D1 & 0 \\
Dopamine D2L & 7 \\
Dopamine D3 & 5 \\
Dopamine D4.2 & 8 \\
Endothelin ETA & 3 \\
Estrogen ER $\alpha$ & -13 \\
GABAA, chloride channel & -9 \\
GABAA, flunitrazepam, central & 2 \\
GABAA, muscimol, central & 6 \\
GABAB, nonselective & -1 \\
GABAB1A & 0 \\
GABAB1B & 5 \\
Glucocorticoid & 2 \\
\hline
\end{tabular}


TABLE 3

Effects of FTBMT in various receptor binding assays (2)

FTBMT was tested at $10 \mu \mathrm{M}$ in the all assays. Negative value of percent inhibition indicates stimulation of receptor activity.

\begin{tabular}{|c|c|}
\hline Receptor & $\%$ Inhibition \\
\hline Glutamate, AMPA & 2 \\
\hline Glutamate, kainite & 2 \\
\hline Glutamate, NMDA, agonism & -7 \\
\hline Glutamate, NMDA, glycine & 3 \\
\hline Glutamate, NMDA, phencyclidine & 4 \\
\hline Glycine, strychnine & -4 \\
\hline Growth hormone secretagogue (ghrelin) & 0 \\
\hline Histamine $\mathrm{H} 1$ & -11 \\
\hline Histamine $\mathrm{H} 2$ & 2 \\
\hline Imidazoline I2, central & 6 \\
\hline Insulin & -9 \\
\hline Muscarinic M1 & 4 \\
\hline Muscarinic M2 & -6 \\
\hline Muscarinic M3 & -6 \\
\hline Nicotinic acetylcholine & -2 \\
\hline Opiate $\delta(\mathrm{OP} 1, \mathrm{DOP})$ & 4 \\
\hline Opiate $\kappa(\mathrm{OP} 2, \mathrm{KOP})$ & -9 \\
\hline Opiate $\mu(\mathrm{OP} 3, \mathrm{MOP})$ & -10 \\
\hline Potassium channel (KATP) & -1 \\
\hline Potassium channel (SKCA) & -1 \\
\hline Progesterone PR-B & 4 \\
\hline Prostanoid, thromboxane A2 (TP) & -6 \\
\hline Serotonin 5-HT1, nonselective & -11 \\
\hline Serotonin 5-HT2, nonselective & 14 \\
\hline Serotonin 5-HT2B & 6 \\
\hline Serotonin 5-HT3 & 10 \\
\hline Serotonin 5-HT4 & 4 \\
\hline Sigma, nonselective & 28 \\
\hline
\end{tabular}

AMPA, $\alpha$-amino-3-hydroxy-5-methyl-4-isoxazolepropionic acid; NMDA, N-methylD-aspartic acid.

(the MEDs for hyperactivity of olanzapine, aripiprazole, and FTBMT were 1, 0.3, and $10 \mathrm{mg} / \mathrm{kg}$, respectively). Moreover, hyperprolactinemia caused by $\mathrm{D} 2 \mathrm{R}$ blockade was not observed in rats treated with FTBMT (3-100 $\mathrm{mg} / \mathrm{kg}$, p.o.), whereas haloperidol ( $1 \mathrm{mg} / \mathrm{kg})$ showed a significant elevation of plasma prolactin level (Fig. 4).

FTBMT Displayed Preferential Activity for Neurons in the NAc Shell Compared with the Striatum In Vivo. FTBMT exhibited a larger separation between doses for antipsychotic-like effects and those for catalepsy compared with olanzapine and aripiprazole. The MEDs for hyperactivity versus catalepsy were $10 \mathrm{mg} / \mathrm{kg}$ versus $>100 \mathrm{mg} / \mathrm{kg}, 1 \mathrm{mg} / \mathrm{kg}$ versus $<1 \mathrm{mg} / \mathrm{kg}$, and $0.3 \mathrm{mg} / \mathrm{kg}$ versus $<0.3 \mathrm{mg} / \mathrm{kg}$ for FTBMT, olanzapine, and aripiprazole, respectively. This may be explained by the activation of different subregions of

TABLE 4

Effects of FTBMT in various receptor binding assays (3)

FTBMT was tested at $10 \mu \mathrm{M}$ in the all assays. Negative value of percent inhibition indicates stimulation of receptor activity.

\begin{tabular}{lr}
\multicolumn{1}{c}{ Receptor } & \% Inhibition \\
\hline Sodium channel, site 2 & 1 \\
Serotonin transporter (SERT) & 8 \\
Tachykinin NK1 & 4 \\
Tachykinin NK2 & -12 \\
Tachykinin NK3 & 20 \\
Transporter, dopamine (DAT) & -1 \\
Transporter, GABA & 2 \\
Transporter, norepinephrine (NET) & 10 \\
Vasopressin V1A & 14 \\
Vasopressin V2 & -1 \\
\hline
\end{tabular}

the striatum and NAc. For example, the activation of medium spiny neurons in the dorsolateral striatum (DLS) has been implicated in antipsychotic-induced catalepsy (Wan et al., 1995; Ohno et al., 2008). Thus, FTBMT-induced neural activation in the DLS, dorsomedial striatum (DMS), and NAc was assessed using c-fos immunohistochemistry. Compared with the vehicle injection, i.p. injection of FTBMT $(30 \mathrm{mg} / \mathrm{kg})$ significantly increased the number of c-fos positive cells in the DMS $(P<0.05)$ and NAc shell $(P<0.01)$, but not in DLS (Fig. 5, A and B).

The brain region-specific activation patterns after treatment with antipsychotics have been quantitatively evaluated using transcriptional changes of several immediate early genes (Nguyen et al., 1992; Robbins et al., 2008; Sakuma et al., 2015). Our previous study (Sakuma et al., 2015) demonstrated that the induction of three immediate early genes, namely, c-fos, Egr-2, and Arc, in the NAc was common after treatment with four antipsychotic drugs (i.e., haloperidol, aripiprazole, olanzapine, and clozapine). Using the same method, the region-specific activation owing to FTBMT application was evaluated and compared with data from our previous study using olanzapine and aripiprazole (Sakuma et al., 2015). Although FTBMT increased the expression of c-fos, Egr-2, and Arc in the NAc to the same levels as olanzapine and aripiprazole, it had a smaller effect in the striatum compared with the other antipsychotic drugs (Fig. 5C).

FTBMT Improved Recognition and Spatial Working Memory in Rats. The effects of FTBMT on cognitive function were assessed using a NORT and radial arm maze test in rats. FTBMT was orally administered to rats at a dose of 3 or $10 \mathrm{mg} / \mathrm{kg}$ immediately after the acquisition trial for NORT. In the retention trial, performed 48 hours after the acquisition trial, FTBMT administration significantly increased the exploration time for novel objects compared with familiar objects (Fig. 6A; $P<0.01$ ) and the novel

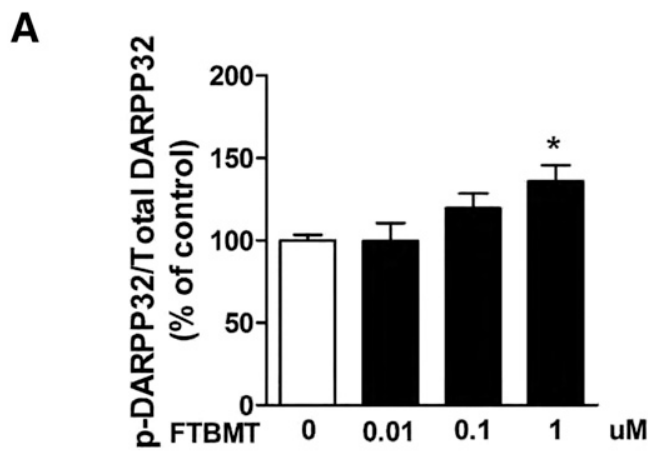

B

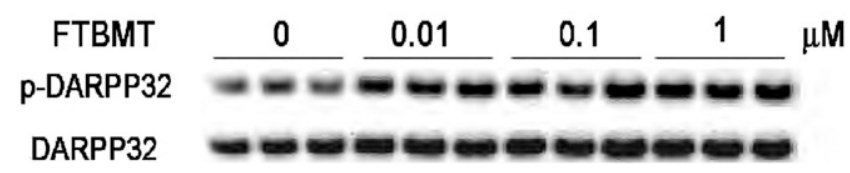

Fig. 2. FTBMT increased phospho-DARPP32 levels in the NAc slices. Acute NAc slices from mouse brains were treated with FTBMT (0.01, 0.1, and $1 \mu \mathrm{M}$ ) for 5 minutes. Phospho-DARPP32 and total DARPP32 in the NAc slices were detected by Western blot analysis (upper panel; representative images), and the corresponding bands were subsequently quantified using densitometry (lower panel; $n=9$, $* P<0.05$ vs. vehicle control). 


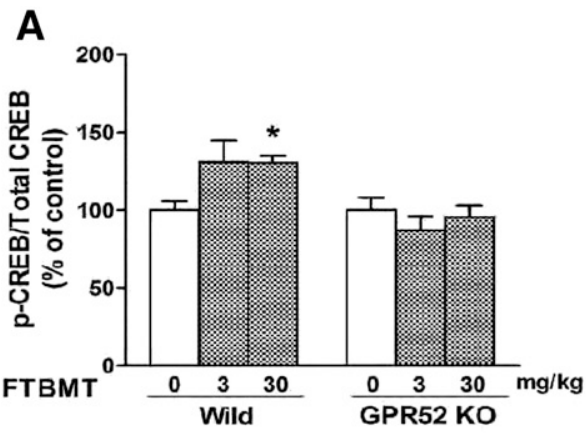

B

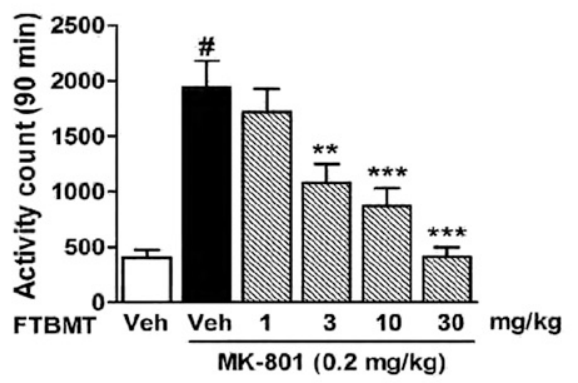

$E$
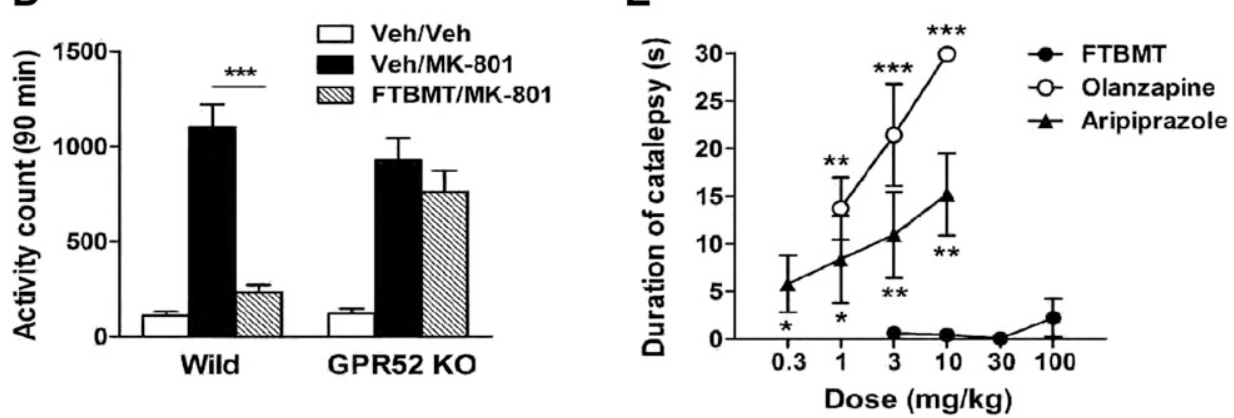

C

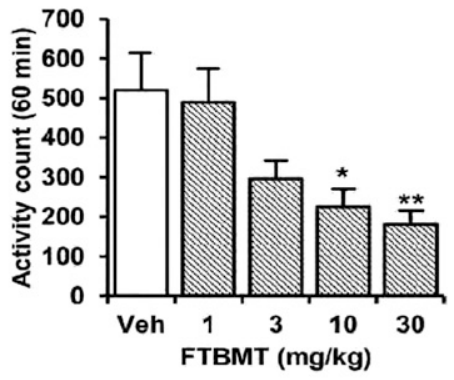

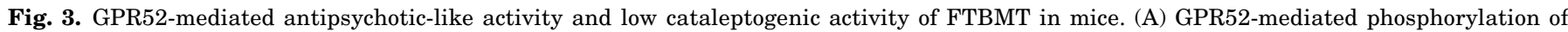

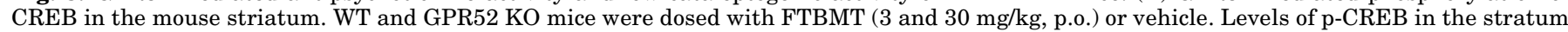

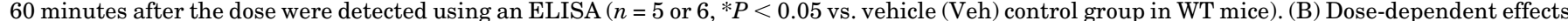

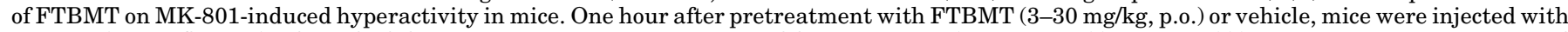

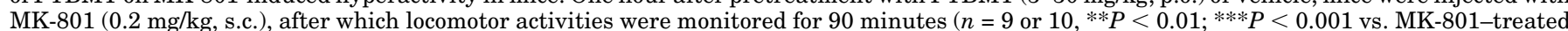

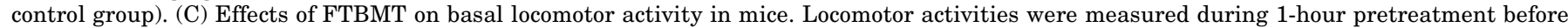

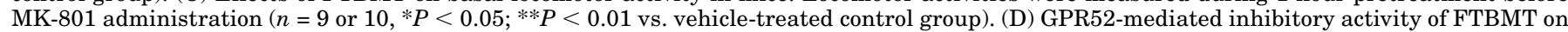

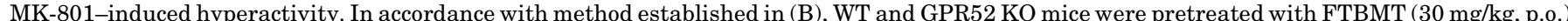

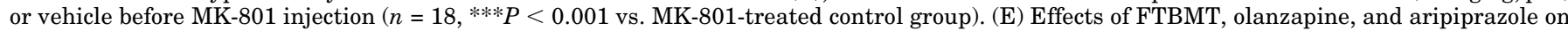

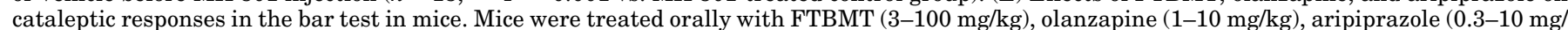

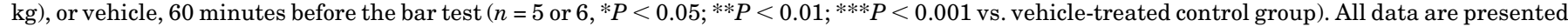
as mean \pm S.E.M.

discrimination index (Fig. 6B; $P<0.01$ ) at both doses, suggesting an improvement in recognition memory. In a radial arm maze test, MK-801 was used to induce impairment of spatial working memory as reflected by the increase in the number of errors (Enomoto et al., 2008). A 1-hour pretreatment with FTBMT (10 mg/kg, p.o.) significantly decreased the number of errors induced by MK-801 (Fig. 6C; $P<0.05$ ), which suggested an improvement in spatial working memory.

FTBMT Stimulated Neuronal Activity in Brain Regions Related to Cognition. GPR52 mRNA was expressed in brain regions related to cognition, including the entorhinal cortex, frontal cortex, and medial prefrontal cortex. As described in Fig. 5A, c-fos immunohistochemistry was used to investigate FTBMT-induced neuronal activation in these brain regions. FTBMT (30 mg/kg, i.p.) significantly increased the number of c-fos-positive neurons in the entorhinal cortex $(P<0.05)$, frontal cortex $(P<0.01)$, and medial prefrontal cortex $(P<0.01)$ (Fig. 7A and B). The entorhinal cortex is commonly perceived as a major input and output structure for hippocampal formation and is considered the hub of corticohippocampal circuits (Preston and Eichenbaum, 2013). Thus, we further assessed activation of the hippocampus, a key region for memory storage. In the hippocampus, oral administration of FTBMT at doses of 3,10 , and $30 \mathrm{mg} / \mathrm{kg}$ significantly induced gene expression of Egr-2 $(P<0.05)$, c-fos $(P<0.01)$, and Arc $(P<0.001)$, respectively (Fig. $7 \mathrm{C})$. The induction of c-fos gene expression in the hippocampus from FTBMT (30 mg/kg, p.o.) diminished in GPR52 KO mice (Fig. 7D,

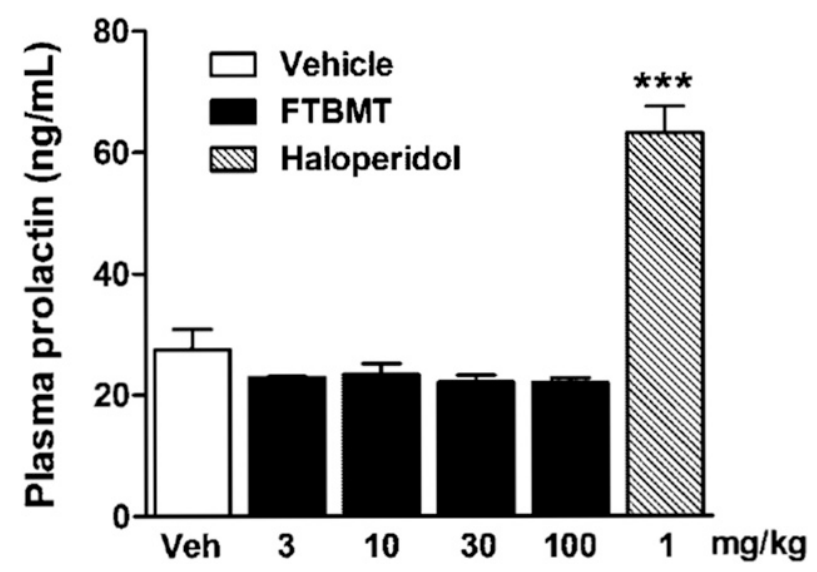

Fig. 4. Effects of FTBMT and haloperidol on plasma prolactin concentrations in rats. FTBMT (3-100 mg/kg), haloperidol $(1 \mathrm{mg} / \mathrm{kg})$, or vehicle was orally administered to rats. One hour later, plasma was collected and prolactin concentration in plasma was measured by ELISA $(n=4, * * * P<$ 0.001 vs. vehicle control). 
A

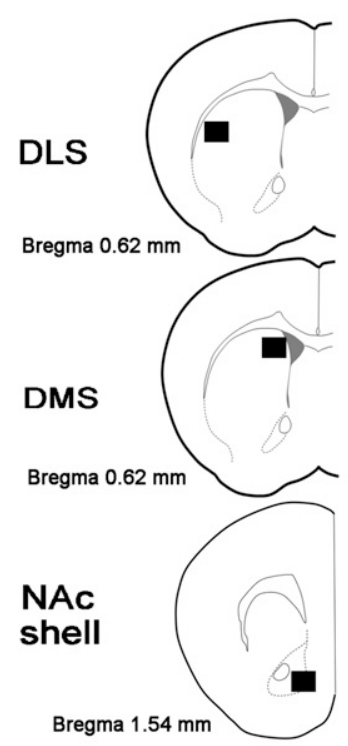

Vehicle
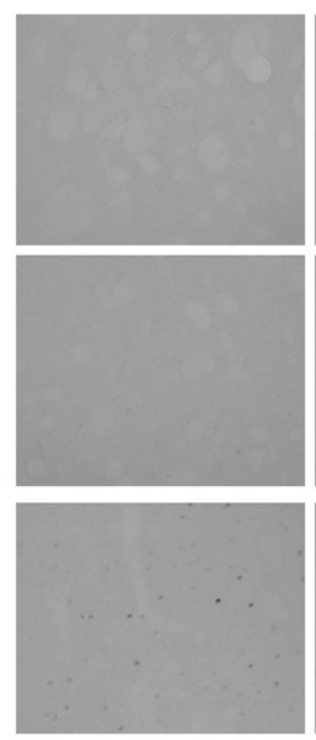

c-fos
FTBMT
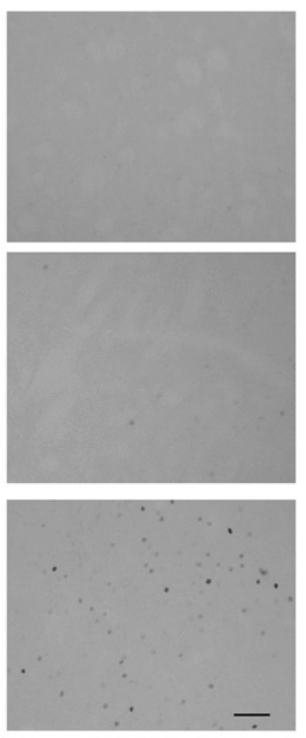

B

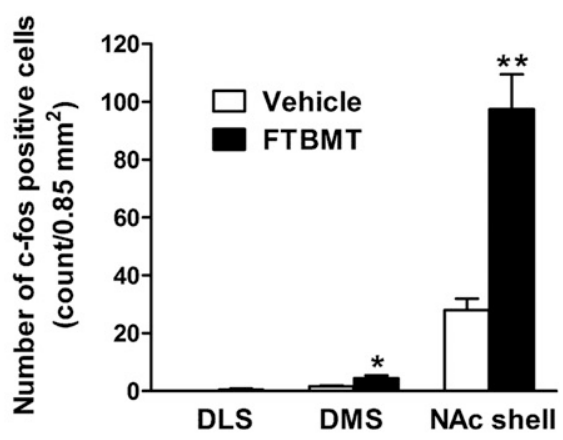

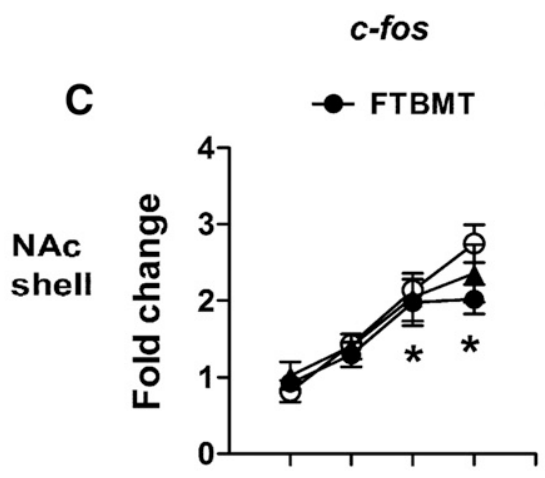

Egr2

Arc

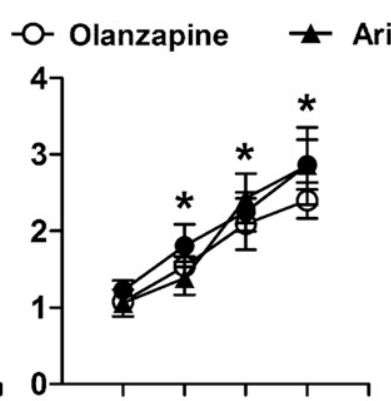

Aripiprazole

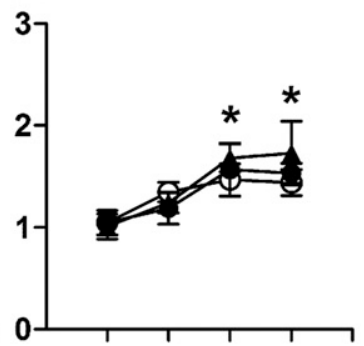

Striatum
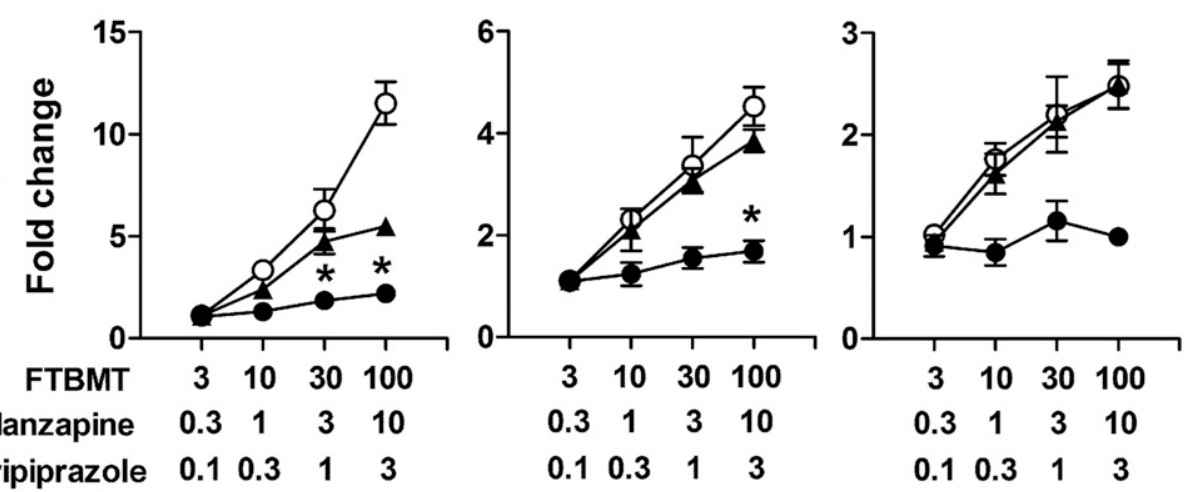

Fig. 5. Preferential activity of FTBMT on neurons in the NAc shell compared with the striatum. (A) Representative photomicrographs of c-fos immunostaining in the DLS, DMS, and NAc shell. The brains of the animals were fixed by perfusion and processed for c-fos immunohistochemical analyses 2 hours after the injection of FTBMT (30 mg/kg, i.p.) or vehicle. Schematic drawings of coronal sections, which were adapted from the mouse brain atlas (Paxinos and Franklin, 2004), were used to count c-fos- positive neurons. Scale bars, $50 \mu \mathrm{m}$. (B) Number of c-fos-positive cells in the DLS, DMS, and NAc ( $n=$ $5, * P<0.05 ; * * P<0.01$ vs. respective vehicle control). (C) Comparison study between the NAc shell and striatum, organized by IEG expression. IEG (i.e., c-fos, Egr-2, and Arc) expression in the NAc shell and striatum taken from mice 1 hour after oral administration of FTBMT (3-100 mg/kg) or vehicle was quantified using qPCR as previously described $(n=5$ or $6, * P<0.05$ vs. vehicle control) (Sakuma et al., 2015). The data on olanzapine (0.3-10 mg/kg, p.o.) and aripiprazole (0.1-3 mg/kg, p.o.) were cited from our previous report (Sakuma et al., 2015). Data are presented as mean \pm S.E.M.

$P<0.001$; a significant main effect of the strain: $F_{1,15}=19.82$, $P<0.01$; significant main effect of the drug: $F_{1,15}=8.52, P<$ 0.01 ; significant strain $\times$ drug interaction: $F_{1,15}=10.99$, $P<0.01$; post-hoc Aspin-Welch test). This activation of hippocampal neurons was confirmed by the increased phosphorylation of CREB, which regulates the synthesis of proteins that are important in the formation of long-term memory in the hippocampus (Barco et al., 2003). 
A

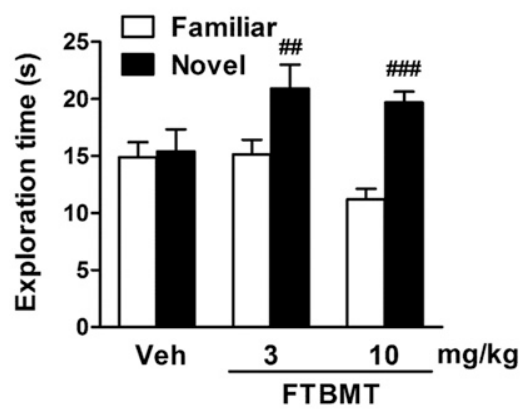

B

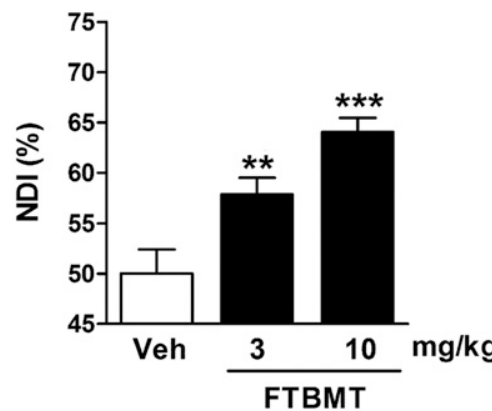

C

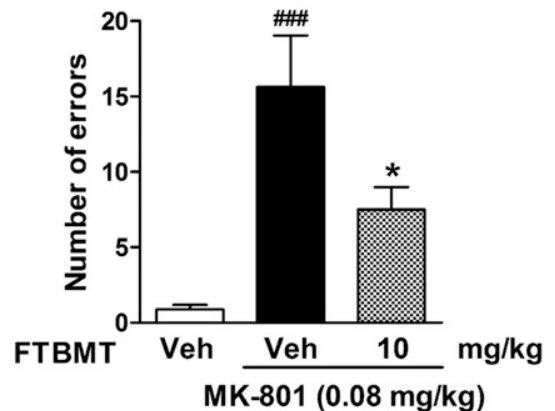

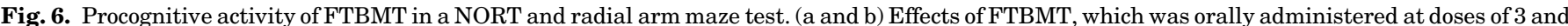

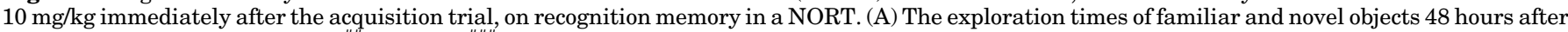

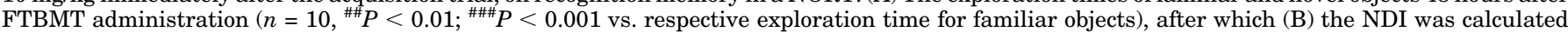

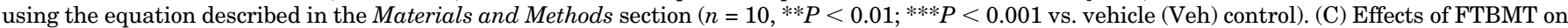

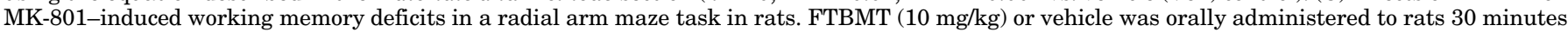

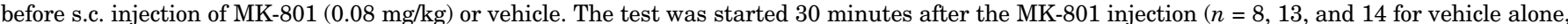

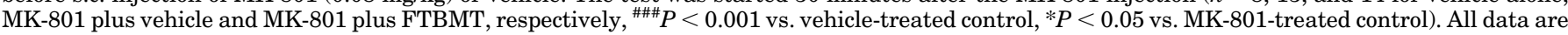
presented as mean \pm S.E.M.

\section{Discussion}

Our study demonstrated that FTBMT functions as a selective GPR52 agonist in vitro and in vivo and has antipsychotic-like and procognitive properties, but no cataleptogenic activity, in rodents. Its behavioral effects were supported by neurochemical findings, such as FTBMT-induced c-fos expression in the NAc shell related to antipsychotic-like effects (Jennings et al., 2006) and in the medial prefrontal cortex, entorhinal cortex, and hippocampus, which are related to cognitive function (Matsuo et al., 2009). These results indicate that FTBMT could be a new therapeutic agent for the treatment of positive and cognitive symptoms of schizophrenia.

On antipsychotic-like activity, FTBMT suppressed MK-801-induced hyperactivity, and it also suppressed basal locomotor activity (Fig. 3B and C), which may suggest that the former effect is not specific for stimulant-evoked portion of locomotor activities; however, similar manner of actions was seen in an A2A-R agonist that showed suppression of MK-801-induced hyperlocomotion at doses where it decreased basal locomotor activity (Malec and Poleszak, 2006). In the case of atypical antipsychotics, such as olanzapine, although some preferentiality for stimulant-evoked hyperlocomotion was seen, separation from the effect on basal locomotor activity was not necesarily wide (Ninan and Kulkarni, 1999). Nevertheless, it is noteworthy that FTBMT did not show cataleptic responses up to 30-fold the MED for antipsychoticlike effects (Fig. 3E).

The data presented in the current study provide new insights into the potential for GPR52 agonists to become a new class of drugs for schizophrenia. Previous studies have highlighted the potential role of GPR52 in targeting the positive symptoms of schizophrenic. Evidence for this hypothesis comes from behavioral studies of methamphetamine responsiveness using GPR52 transgenic mice and the GPR52 agonist compound 7m (Komatsu et al., 2014; Setoh et al., 2014); however, there is a lack of biochemical evidence to support and understand these behavioral data. In the current study, we used biochemical analyses to demonstrate that FTBMT activated cAMP signaling in vitro and in vivo. GPR52-mediated cAMP signaling was evaluated in the neurons of the striatum and NAc. FTBMT increased intracellular cAMP, phospho-CREB, and IEG expression in primary striatal neurons (Fig. 1C, D and E). Moreover, FTBMT increased the basal and NMDA-stimulated release of GABA in primary striatal neurons (Fig. 1F). In line with these findings, FTBMT increased phospho-CREB levels via GPR52 in the striatum in vivo (Fig. 3A). These pharmacologic effects are quite similar to those of A2A-R agonists. Activation of A2A-R in striatopallidal GABAergic neurons counteracts changes in the cAMP level after Gi-coupled D2R signaling, thus increasing GABA release and leading to the inhibition of amphetamine-induced hyperactivity (Rimondini et al., 1997; Kull et al., 1999; Khisti et al., 2000). CREB signaling, which occurs downstream of cAMP signaling, also impacts both the dopamine and glutamate systems in the striatum (Greengard et al., 1999). Some dissociation was seen between the effective doses in behavioral tests and those in biochemical assays, possibly because of the limitation of tissue sampling that does not necessarily collect responsible neurons for some specific behavioral effect, resulting in lower sensitivity. Nevertheless, the present biochemical findings qualitatively support the antipsychotic-like activity of FTBMT.

We also evaluated the effects of FTBMT in pharmacologic models based on the glutamate hypothesis. Since protein kinase A directly regulates NMDA receptor-mediated $\mathrm{Ca}^{2+}$ increases, GPR52 activation was expected to potentiate NMDA receptor signaling via cAMP signaling (Skeberdis et al., 2006). FTBMT reversed NMDA receptor blocker MK-801-induced hyperactivity and cognitive impairment (Fig. 3B and 6C). In addition, FTBMT enhanced NMDA-evoked GABA release in primary striatal neurons (Fig. 1F). These results suggest that FTBMT may enhance NMDA receptor functions.

Next, we demonstrated a potential mechanism by which FTBMT had no cataleptogenic activity. Atypical antipsychotic agents reduce EPS liability, probably owing to their weak D2R and potent $5-\mathrm{HT}_{2 \mathrm{~A}}$ receptor antagonism (Meltzer, 1999); however, FTBMT had a wider safety margin compared with atypical antipsychotics, such as olanzapine and aripiprazole (Fig. 3D). This profile is similar to some potential 
A

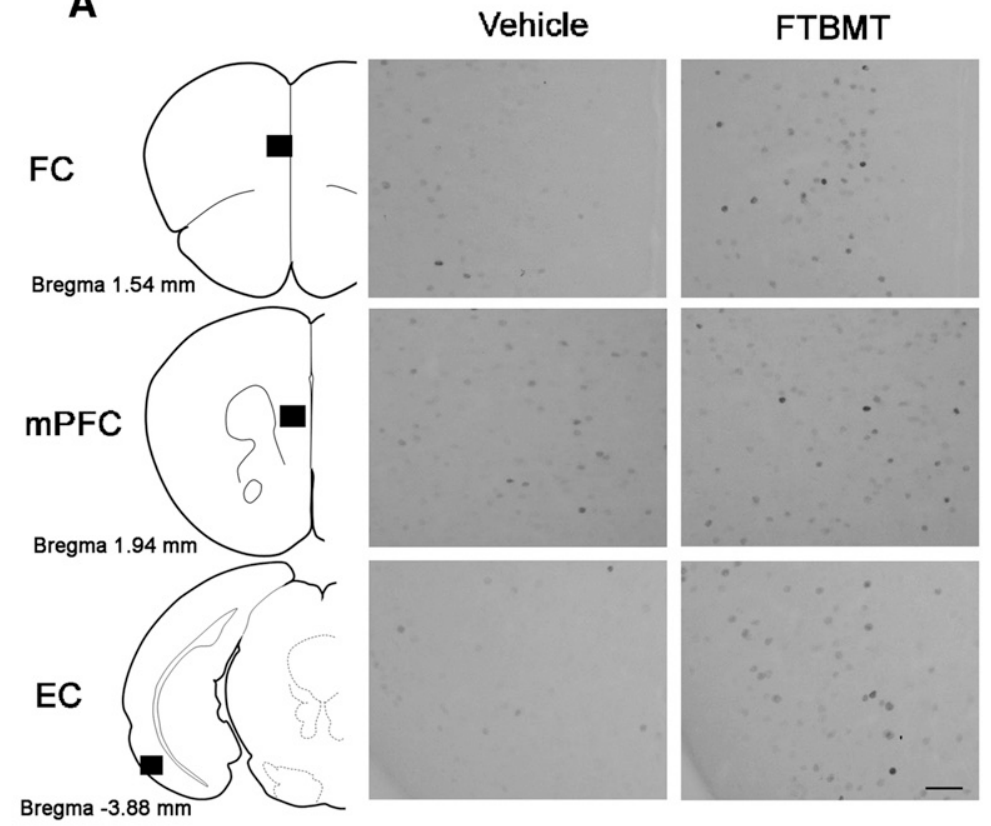

B

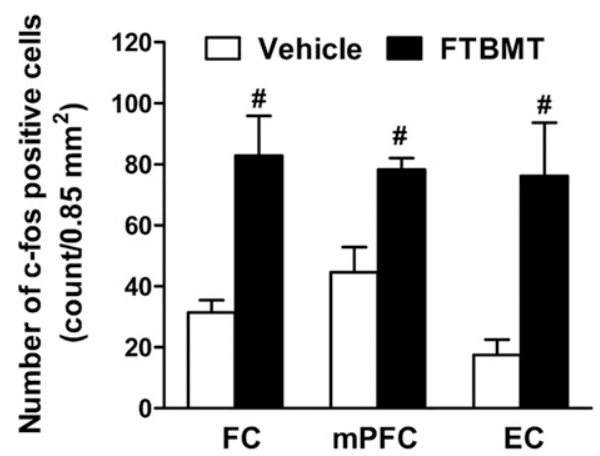

E

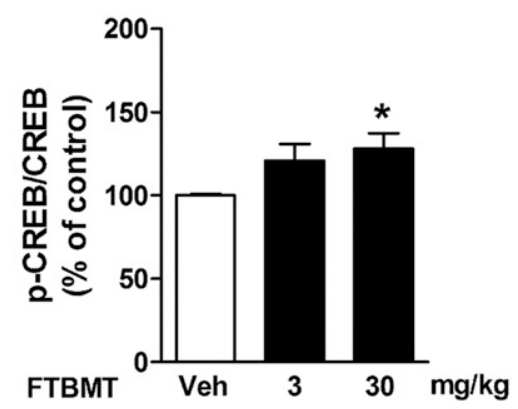

Fig. 7. FTBMT-induced neuronal activation in brain regions related to cognition. (A) Photomicrographs showing c-fos-positive neurons in the frontal cortex (FC), medial prefrontal cortex (mPFC), and entorhinal cortex (EC). Immunohistochemical analyses of c-fos were performed as described in Fig. 5A. Scale bars, $50 \mu \mathrm{m}$. (B) Number of c-fos- positive cells in the FC, mPFC, and EC ( $n=5$ ). Induction of (C and D) IEG expression and (E) p-CREB by FTBMT in the hippocampus. Two hours after the administration of FTBMT (3-30 mg/kg, p.o.) to (C and E) naïve mice and (D) GPR52 KO mice and WT littermates, the hippocampal tissues were collected and analyzed using gene expression assays (C; $n=6$ or 7 , D; $n=4$ or 5 ) and an ELISA for p-CREB (E; $n=4$ or 5 ). ${ }^{*} P<0.05 ;{ }^{*} P<0.01 ;{ }^{\#} P<0.05 ;{ }^{\&} P<0.05$ vs. respective vehicle (Veh)-treated controls. All data are presented as mean \pm S.E.M.

antipsychotic agents, such as the A2A-R agonist CGS 21680, the metabotropic glutamate receptor 1 allosteric antagonist CFMTI, and the phosphodiesterase 10A inhibitor TAK-063 (Rimondini et al., 1997; Satow et al., 2009; Suzuki et al., 2015). Among these, CGS 21680 and CFMTI increased c-fos-positive neurons in the NAc shell, but not in the DLS, which was similar to the results observed with FTBMT (Fig. 5A and B) (Pinna et al., 1997; Satow et al., 2009). The findings from c-fos immunohistochemical staining were validated with the comparison studies of region-specific IEG expression using FTBMT, olanzapine, and aripiprazole (Fig. 5C). Given that the NAc has been proposed as the central therapeutic site of activity for antipsychotics, the preferential neuronal activation in the NAc may reflect the antipsychotic-like activity of FTBMT, without catalepsy induction (Epstein et al., 1999; Raij et al., 2009; Jones et al., 2011); however, the mechanism by which FTBMT preferentially induces neuronal activation in the NAc remains to be elucidated.
Finally, we demonstrated that FTBMT improved cognitive functions associated with the medial prefrontal cortex, frontal cortex, and hippocampus. Seven cognitive domains that are commonly disrupted in schizophrenia, identified by the Measurement and Treatment Research to Improve Cognition in Schizophrenia initiative, were as follows: attention/vigilance, working memory, reasoning and problem solving, processing speed, visual learning and memory, verbal learning and memory, and social cognition (Nieuwenstein et al., 2001). Among these cognitive domains, the NORT and radial arm maze test could be used to probe visual learning and memory and working memory in rodents (Young et al., 2009). In these tests, FTBMT improved both cognitive functions in rats. Previous behavioral studies have demonstrated that the medial prefrontal cortex is important for working memory in the radial arm maze test, whereas the frontal cortex and hippocampus are involved in visual learning and memory in the NORT (Clark et al., 2000; Taylor et al., 2003; Nagai et al., 2007). Thus, the increased neuronal activity in the 
frontal cortex, medial prefrontal cortex, entorhinal cortex, and hippocampus with FTBMT corroborated with these previous results. The changes in these brain regions may represent the activation of the prefrontal-entorhinal-hippocampus circuit, which plays a crucial role in the encoding and retrieval of memories (Preston and Eichenbaum, 2013).

The results from the current study provided some evidence that GPR52 could be a potential therapeutic target in schizophrenia; however, elucidation of its etiologic role in the condition is still required for validation. To the extent of our knowledge, there is no evidence to demonstrate the association between GPR52 and schizophrenia in human genetic and pathologic studies. Since GPR52 is still an orphan receptor, the identification of its corresponding endogenous ligand may lead to new findings about its etiologic link with schizophrenia.

In conclusion, given its antipsychotic and procognitive properties without causing catalepsy in rodent models, FTBMT, a selective and potent GPR52 agonist, may provide a new therapeutic option for the treatment of positive and cognitive symptoms of schizophrenia.

\section{Acknowledgments}

We thank Hiroyuki Ota for providing technical advice on behavioral assays. We also thank Yoshiteru Itoh for the synthesis and supply of FTBMT.

\section{Authorship Contributions}

Participated in research design: Nishiyama, H. Suzuki, Harasawa, N. Suzuki, Kurimoto, Kawai, Maruyama, Komatsu, Sakuma, Shimizu, Shimojo.

Conducted experiments: Nishiyama, H. Suzuki, Harasawa, N. Suzuki, Kurimoto, Kawai, Maruyama, Komatsu, Sakuma, Shimizu.

Performed data analysis: Nishiyama, H. Suzuki, Harasawa, N. Suzuki, Kurimoto, Kawai, Maruyama, Komatsu, Sakuma, Shimizu.

Wrote or contributed to the writing of the manuscript: Nishiyama wrote the first draft with contribution of all authors. Shimojo revised the draft and prepared the final version.

\section{References}

Algina J (2005) Aspin welch test, in Encyclopedia of Biostatics, John Wiley \& Sons, Ltd., New York.

Barco A, Pittenger C, and Kandel ER (2003) CREB, memory enhancement and the treatment of memory disorders: promises, pitfalls and prospects. Expert Opin Ther Targets 7:101-114

Bevins RA and Besheer J (2006) Object recognition in rats and mice: a one-trial nonmatching-to-sample learning task to study recognition memory. Nat Protoc 1:1306-1311.

Clark RE, Zola SM, and Squire LR (2000) Impaired recognition memory in rats after damage to the hippocampus. J Neurosci 20:8853-8860.

Enomoto T, Ishibashi T, Tokuda K, Ishiyama T, Toma S, and Ito A (2008) Lurasidone reverses MK-801-induced impairment of learning and memory in the Morris water maze and radial-arm maze tests in rats. Behav Brain Res 186:197-207.

Epstein J, Stern E, and Silbersweig D (1999) Mesolimbic activity associated with psychosis in schizophrenia: symptom-specific PET studies. Ann N Y Acad Sci 877:562-574.

Ferré S, Quiroz C, Woods AS, Cunha R, Popoli P, Ciruela F, Lluis C, Franco R, Azdad $\mathrm{K}$, and Schiffmann SN (2008) An update on adenosine A2A-dopamine D2 receptor interactions: implications for the function of $\mathrm{G}$ protein-coupled receptors. Curr Pharm Des 14:1468-1474.

Fraser HS (1996) Reserpine: a tragic victim of myths, marketing, and fashionable prescribing. Clin Pharmacol Ther 60:368-373.

Goff DC and Coyle JT (2001) The emerging role of glutamate in the pathophysiology and treatment of schizophrenia. Am J Psychiatry 158:1367-1377.

Greengard P, Allen PB, and Nairn AC (1999) Beyond the dopamine receptor: the DARPP-32/protein phosphatase-1 cascade. Neuron 23:435-447.

Jennings CA, Cluderay JE, Gartlon J, Cilia J, Lloyd A, Jones DN, and Southam E (2006) The effects of ziprasidone on regional c-Fos expression in the rat forebrain. Psychopharmacology (Berl) 184:13-20.

Jones CA, Watson DJ, and Fone KC (2011) Animal models of schizophrenia. $\mathrm{Br} J$ Pharmacol 164:1162-1194.

Khisti RT, Chopde CT, and Abraham E (2000) GABAergic involvement in motor effects of an adenosine $\mathrm{A}(2 \mathrm{~A})$ receptor agonist in mice. Neuropharmacology 39: $1004-1015$.

Kingwell K (2014) Schizophrenia drug gets negative results for negative symptoms. Nat Rev Drug Discov 13:244-245.
Komatsu H, Maruyama M, Yao S, Shinohara T, Sakuma K, Imaichi S, Chikatsu T, Kuniyeda K, Siu FK, Peng LS, et al. (2014) Anatomical transcriptome of G proteincoupled receptors leads to the identification of a novel therapeutic candidate GPR52 for psychiatric disorders. PLoS One 9:e90134.

Krebs M, Leopold K, Hinzpeter A, and Schaefer M (2006) Current schizophrenia drugs: efficacy and side effects. Expert Opin Pharmacother 7:1005-1016.

Kull B, Ferré S, Arslan G, Svenningsson P, Fuxe K, Owman C, and Fredholm BB (1999) Reciprocal interactions between adenosine A2A and dopamine D2 receptors in Chinese hamster ovary cells co-transfected with the two receptors. Biochem Pharmacol 58:1035-1045.

Li ML, Hu XQ, Li F, and Gao WJ (2015) Perspectives on the mGluR2/3 agonists as a therapeutic target for schizophrenia: still promising or a dead end? Prog Neuropsychopharmacol Biol Psychiatry 60:66-76.

Malec D and Poleszak E (2006) Involvement of adenosine receptors in dizocilpineinduced motor activity in mice. Pharmacol Rep 58:101-106.

Matsuo N, Yamasaki N, Ohira K, Takao K, Toyama K, Eguchi M, Yamaguchi S, and Miyakawa T (2009) Neural activity changes underlying the working memory deficit in alpha-CaMKII heterozygous knockout mice. Front Behav Neurosci 3:20.

Meltzer HY (1999) The role of serotonin in antipsychotic drug action. Neuropsychopharmacology 21 (2, Suppl):106S-115S.

Miyamoto S, Miyake N, Jarskog LF, Fleischhacker WW, and Lieberman JA (2012) Pharmacological treatment of schizophrenia: a critical review of the pharmacology and clinical effects of current and future therapeutic agents. Mol Psychiatry 17:1206-1227.

Nagai T, Takuma K, Kamei H, Ito Y, Nakamichi N, Ibi D, Nakanishi Y, Murai M, Mizoguchi H, Nabeshima T, et al. (2007) Dopamine D1 receptors regulate protein synthesis-dependent long-term recognition memory via extracellular signalregulated kinase 1/2 in the prefrontal cortex. Learn Mem 14:117-125.

Nakazawa K, Zsiros V, Jiang Z, Nakao K, Kolata S, Zhang S, and Belforte JE (2012) GABAergic interneuron origin of schizophrenia pathophysiology. Neuropharmacology 62:1574-1583

Nguyen TV, Kosofsky BE, Birnbaum R, Cohen BM, and Hyman SE (1992) Differential expression of c-fos and zif268 in rat striatum after haloperidol, clozapine, and amphetamine. Proc Natl Acad Sci USA 89:4270-4274.

Nieuwenstein MR, Aleman A, and de Haan EH (2001) Relationship between symptom dimensions and neurocognitive functioning in schizophrenia: a meta-analysis of WCST and CPT studies. Wisconsin card sorting test. Continuous performance test. J Psychiatr Res 35:119-125.

Ninan I and Kulkarni SK (1999) Preferential inhibition of dizocilpine-induced hyperlocomotion by olanzapine. Eur J Pharmacol 368:1-7.

Nishi A, Kuroiwa M, Miller DB, O'Callaghan JP, Bateup HS, Shuto T, Sotogaku N, Fukuda T, Heintz N, Greengard P, et al. (2008) Distinct roles of PDE4 and PDE10A in the regulation of cAMP/PKA signaling in the striatum. $J$ Neurosci 28: 10460-10471.

Ohno Y, Shimizu S, Imaki J, Ishihara S, Sofue N, Sasa M, and Kawai Y (2008) Anticataleptic 8-OH-DPAT preferentially counteracts with haloperidol-induced Fos expression in the dorsolateral striatum and the core region of the nucleus accumbens. Neuropharmacology 55:717-723.

O'Neill MF and Shaw G (1999) Comparison of dopamine receptor antagonists on hyperlocomotion induced by cocaine, amphetamine, MK-801 and the dopamine D1 agonist C-APB in mice. Psychopharmacology (Berl) 145:237-250.

Paxinos G and Franklin KB (2004) Mouse Brain in Stereotaxic Coordinates, Academic Press, New York.

Pinna A, Wardas J, Cristalli G, and Morelli M (1997) Adenosine A2A receptor agonists increase Fos-like immunoreactivity in mesolimbic areas. Brain Res 759:41-49.

Preston AR and Eichenbaum H (2013) Interplay of hippocampus and prefrontal cortex in memory. Curr Biol 23:R764-R773.

Raij TT, Valkonen-Korhonen M, Holi M, Therman S, Lehtonen J, and Hari R (2009) Reality of auditory verbal hallucinations. Brain 132:2994-3001.

Rimondini R, Ferré S, Ogren SO, and Fuxe K (1997) Adenosine A2A agonists: a potential new type of atypical antipsychotic. Neuropsychopharmacology 17:82-91. Robbins MJ, Critchlow HM, Lloyd A, Cilia J, Clarke JD, Bond B, Jones DN, and Maycox PR (2008) Differential expression of IEG mRNA in rat brain following acute treatment with clozapine or haloperidol: a semi-quantitative RT-PCR study. J Psychopharmacol 22:536-542.

Saha S, Chant D, Welham J, and McGrath J (2005) A systematic review of the prevalence of schizophrenia. PLoS Med 2:e141.

Sakuma K, Komatsu H, Maruyama M, Imaichi S, Habata Y, and Mori M (2015) Temporal and spatial transcriptional fingerprints by antipsychotic or propsychotic drugs in mouse brain. PLoS One 10:e0118510.

Sarpal DK, Robinson DG, Lencz T, Argyelan M, Ikuta T, Karlsgodt K, Gallego JA Kane JM, Szeszko PR, and Malhotra AK (2015) Antipsychotic treatment and functional connectivity of the striatum in first-episode schizophrenia. JAMA Psychiatry 72:5-13.

Satow A, Suzuki G, Maehara S, Hikichi H, Murai T, Murai T, Kawagoe-Takaki H, Hata M, Ito S, Ozaki S, et al. (2009) Unique antipsychotic activities of the selective metabotropic glutamate receptor 1 allosteric antagonist 2-cyclopropyl-5-[1-(2fluoro-3-pyridinyl)-5-methyl-1H-1,2,3-triazol-4-yl]-2,3-dihydro-1H-isoindol-1-one. $J$ Pharmacol Exp Ther 330:179-190.

Sawzdargo M, Nguyen T, Lee DK, Lynch KR, Cheng R, Heng HH, George SR, and O'Dowd BF (1999) Identification and cloning of three novel human G proteincoupled receptor genes GPR52, PsiGPR53 and GPR55: GPR55 is extensively expressed in human brain. Brain Res Mol Brain Res 64:193-198.

Setoh M, Ishii N, Kono M, Miyanohana Y, Shiraishi E, Harasawa T, Ota H, Odani T, Kanzaki N, Aoyama K, et al. (2014) Discovery of the first potent and orally available agonist of the orphan G-protein-coupled receptor 52. J Med Chem 57:5226-5237.

Shindou T, Nonaka H, Richardson PJ, Mori A, Kase H, and Ichimura M (2002) Presynaptic adenosine A2A receptors enhance GABAergic synaptic transmission via a cyclic AMP dependent mechanism in the rat globus pallidus. $\mathrm{Br} J$ Pharmacol 136:296-302. 
Shiraishi E, Suzuki K, Harada A, Suzuki N, and Kimura H (2016) The phosphodiesterase 10A selective inhibitor TAK-063 improves cognitive functions associated with schizophrenia in rodent models. J Pharmacol Exp Ther $\mathbf{3 5 6}$ $587-595$.

Shirley E (1977) A non-parametric equivalent of Williams' test for contrasting increasing dose levels of a treatment. Biometrics 33:386-389.

Skeberdis VA, Chevaleyre V, Lau CG, Goldberg JH, Pettit DL, Suadicani SO, Lin Y, Bennett MV, Yuste R, Castillo PE, et al. (2006) Protein kinase A regulates calcium permeability of NMDA receptors. Nat Neurosci 9:501-510.

Snedecor GW and Cochran WG (1989) in Statistical Methods, 8th ed, Iowa State University Press, Ames.

Suzuki K, Harada A, Shiraishi E, and Kimura H (2015) In vivo pharmacological characterization of TAK-063, a potent and selective phosphodiesterase $10 \mathrm{~A}$ inhibitor with antipsychotic-like activity in rodents. J Pharmacol Exp Ther $\mathbf{3 5 2}$ 471-479.

Taylor CL, Latimer MP, and Winn P (2003) Impaired delayed spatial win-shift behaviour on the eight arm radial maze following excitotoxic lesions of the medial prefrontal cortex in the rat. Behav Brain Res 147:107-114.

Tokumaru K, Ito Y, Nomura I, Nakahata T, Shimizu Y, Kurimoto E, Aoyama K and Aso K (2017) Design, synthesis, and pharmacological evaluation of 4-azolyl-benzamide derivatives as novel GPR52 agonists. Bioorg Med Chem 25:3098-3115.

Wan W, Ennulat DJ, and Cohen BM (1995) Acute administration of typical and atypical antipsychotic drugs induces distinctive patterns of Fos expression in the rat forebrain. Brain Res 688:95-104.

Williams DA (1971) A test for differences between treatment means when several dose levels are compared with a zero dose control. Biometrics 27:103-117.

Young JW, Powell SB, Risbrough V, Marston HM, and Geyer MA (2009) Using the MATRICS to guide development of a preclinical cognitive test battery for research in schizophrenia. Pharmacol Ther 122:150-202.

Zou LB, Yamada K, and Nabeshima T (1998) Sigma receptor ligands (+)-SKF10,047 and SA4503 improve dizocilpine-induced spatial memory deficits in rats. Eur $J$ Pharmacol 355:1-10.

Address correspondence to: Dr. Masato Shimojo, CNS Drug Discovery Unit, Research, Takeda Pharmaceutical Company Ltd. 26-1, Muraoka-Higashi 2-chome, Fujisawa, Kanagawa 251-8555, Japan. E-mail: masato.shimojo@ takeda.com 